Jurnal Media

Teknik dan

Sistem Industri
Jurnal Media Teknik \& Sistem Industri

Vol. 5 (no. 2) (2021) hal. 83 - 91

http://jurnal.unsur.ac.id/JMTSI e-issn: 2581-0561

p-issn: 2581-0529

DOI : 10.35194/jmtsi.v5i2.1435

\title{
Minimasi Kecacatan pada Produk Kemasan Kedelai Menggunakan Six Sigma, FMEA dan Seven Tools di PT. SATP
}

\author{
Bagas Satria Wijaya ${ }^{1 *}$, Deny Andesta ${ }^{2}$, Efta Dhartikasari Priyana $^{3}$ \\ ${ }^{1,3}$ Teknik Industri Universitas Muhammadiyah Gresik \\ Jl. Sumatera No.101 Gresik, Jawa Timur 61121 \\ 1*bagas_170601@umg.ac.id \\ ${ }^{2}$ deny_andesta@umg.ac.id \\ 3eftadhartikasari@umg.ac.id
}

\section{Minimizing Defects in Soybean Packaging Products Using Six Sigma, FMEA and Seven Tools at PT. SATP}

Dikirimkan : 05, 2021. Diterima : 08, 2021. Dipublikasikan : 09, 2021

\begin{abstract}
PT Sari Agro Tama Persada is a company engaged in the agribusiness industry. In the business world, quality is a determining factor in customer buying interest. Many new business actors, PT Sari Agro Tama Persada (SATP) must be careful in maintaining and even improving the quality of their products. To control the quality, the methods used are six sigma, FMEA and seven tools. The Six Sigma method is a procedure to identify the triggers of defects in products or processes by correcting cases and improving quality with Define, Measure, Analysis, Improve, Control (DMAIC), Failure Mode and Effect Analysis (FMEA) is used to determine the RPN value on the PT SATP problem of 245 in poor quality sacks. Based on the calculation of the Defecr Per Million Opportunity (DPMO) value that has been carried out, the highest value is 2284,595 , while the highest defect in torn sacks is 75 sacks with a percentage of 39.89 . For the sigma $(\alpha)$ value of 4.97. In the cause-and-effect diagram, there are suggestions for improvements that will minimize defects, namely: carrying out extra supervision of workers, conducting safety briefings/talks before work, checking machines, and prioritizing the availability of spare parts (sewing needles), performing routine calibrations on machines balance.
\end{abstract}

Keywords:Packaging; Six sigma; FMEA; DMAIC; Fishbone diagram

\begin{abstract}
Abstrak- PT Sari Agro Tama Persada merupakan perusahaan yang bergerak di industri agribisnis. Dalam dunia bisnis, kualitas merupakan faktor penentu pada minat beli customer. Banyaknya pelaku usaha baru, PT Sari Agro Tama Persada (SATP)harus berhati-hati dalam menjaga bahkan meningkatkan kualitas produknya. Untuk mengendalikan kualitas mutu di gunakan metode yaitu six sigma, FMEA dan seven tools. Metode Six Sigma ialah prosedur untuk mengenali pemicu kecacatan pada produk ataupun proses dengan membetulkan kasus serta tingkatkan mutu dengan Define, Measure, Analysis, Improve, Control (DMAIC), Failure Mode and Effect Analysis (FMEA) digunakan untuk mengetahui nilai RPN pada permasalahan PT SATP sebesar 245 pada kualitas karung yang buruk. Berdasarkan penghitungan nilai Defecr Per Million Opportunity (DPMO) yang telah dilakukan didapat nilai tertinggi 2284.595, sedangkan cacat tertinggi pada kemasan karung sobek sebesar 75 karung dengan persentase 39.89. Untuk nilai $\operatorname{sigma}(\alpha)$ sebesar 4.97. Pada diagram sebab-akibat, terdapat usulan perbaikan akan meminimalisir defect yaitu : melakukan pengawasan ekstra pada pekerja, di lakukan briefieng/safety talk pada saat sebelum bekerja, melakukan pengecekan mesin, serta mementingkan ketersediaan spare part (jarum jahit), melakukan kalibrasi rutin pada mesin timbangan.

Kata kunci: Pengemasan; Six sigma; FMEA; DMAIC; Diagram sebab-akibat.

Copyright $(\odot$---- THE AUTHOR(S).This article is distributed under a Creative Commons Attribution-Share Alike 4.0 International license. Jurnal Media Teknik dan Sistem Industri is published by Industrial Engineering of Universitas Suryakancana
\end{abstract}




\section{PENDAHULUAN}

Persaingan industri di masa globalisasi mengharuskan seluruh industri baik di bidang jasa maupun manufaktur dapat menaikkan kualitas terhadap pelayanan produk. Hal tersebut dimaksudkan untuk menghadapi tantangan jaman yang semakin hari kian ketat. Kualitas merupakan salah satu kunci utama sesuatu industri dapat survive mempertahankan pasar, karena dengan kualitas yang baik dapat menggambarkan suatu kepercayaan tersendiri di mata pelanggan.

Keberhasilan suatu produk dapat tercapai salah satunya dengan adanya kualitas yang baik dari kacamata pelanggan. Hal tersebut selaras dengan yang dipaparkan oleh [1]bahwa keakuratan modal yang dikeluarkan, keakuratan waktu penerapan serta hasil kualitas sesuai dengan harapan pelanggan dan juga mengungkapkan bahwa untuk meningkatkan kualitas sumber daya manusia serta kesanggupan untuk memanfaatkan sumber daya alam, salah satu faktornya yaitu kualitas produk yang dihasilkan di PT. Tembaga Mulia Semanan [2].

Tercatat pada tahun 2020 penduduk Indonesia telah mencapai 270.203.917 juta jiwa [3]dengan supplay kebutuhan kedelai mencapai 992.952 Ton. Dengan rasio 0,004 kebutuhan kedelai dengan total penduduk di Indonesia, membuat pasar kedelai merupakan salah satu pasar yang cukup menjanjikan.

Salah satu industri kedelai yang ada di Indonesia adalah PT Sari Agro Tama Persada, yang merupakan salah satu industri penghasil kedelai (import) dengan kapasitas produksi ratarata sebesar 218 Ton dalam 14 hari.Namunproduksi tersebut tidak bisa dilepaskan penuh ke pasaran, karena terjadi kegagalan dalam proses produksi. Kegagalan paling banyak mendapatkan complain dari customer adalah proses produksi packaging. Complain kecacatan tersebut antara lain kemasan karung sobek sebesar 75 karung, jahitan karung lepas sebesar 56 karung dan gagal timbang sebesar 57 karung (isi kapasitas produk tidak sesuai) serta dengan jumlah produksi sebesar 61280 karung(pada saat di lakukannya penelitian).Kegagalan yang paling banyak di terima adalah pada pengemasan (packaging).

Kualitas menjadi permasalahan mendasar pada pertimbangan konsumen dalam memilih produk ataupun service, semisal proses produksi pada suatu perusahaan manufaktur terjadi banyaknya produk yang cacat, sehingga konsumen akan mudah beralih memilih produk lain atau perusahaan lain yang menawari produk yang selaras, namun dengan kualitas yang berbeda[4]. Sebuah industri akan sukses jika memperoleh pelanggan dalam jumlah yang banyak dan bisa membagikan kepuasan untuk konsumen [5].

Terdapatnya kegagalan yang terus berkepanjangan, dan banyaknya complain yang masuk, membuat peneliti ingin membuat serangkaian pengendalian kualitas untuk meminimalisir kegagalan yang terjadi, utamanya pada produk packaging di PT Sari Agro Tama Persada. Dengan terjadinya problem statement tersebut, di gunakannya 3 metode ini akan lebih mudah untuk mencari permasalahan pada peningkatan produksi, mengurangi cacat produk, dan meningkatkan pertumbuhan pangsa pasar (Six Sigma), serta mengidentifikasi dan memahami akan mode kegagalan dan penyebab efek kegagalan pada sistem (FMEA) dan juga sebagai analisa penyimpangan pada produk cacat serta mencari penyebab permasalahan produk cacat agar tidak terulang kembali (Seven Tools).

Berdasarkan permasalahan yang di hadapi PT. SATP, tepat gunanya peneliti menggunakan 3 metode tersebut, agar terpecahnya problem statement tersebut (defect produk kemasan) dan juga sebagai acuan untuk menerapkan Zero Defect pada perusahaan.

\section{Metodologi PENELITIAN}

Untuk memecahkan masalah serta kerangka pemikiran penelitian, digunakan langkah-langkah metode penelitian yang sistematis dan memiliki tujuan, dengan menerapkan proses Define, Measure, Analyze, Improve, Control (DMAIC) pada Six Sigma, menggunakan Seven Tools untuk mengetahui (checksheet, stratifikasi, histogram, diagram pencar, diagram pareto, peta kendali dan fishbone diagram) dan FMEA untuk mengetahui nilai Risk Priority Number (RPN) dan sebagai usulan perbaikan pada proses pengemasan produk kedelai untuk ke depannya Penelitian ini dilaksanakan di PT Sari Agro Tama Persada Gresik beralamatkan di jalan kapten Darmo Sugondo No.56 Kebomas-Gresik.

Penelitian ini memiliki alur, pertama melakukan pengumpulan data produksi dan kegagalan, kedua merangking/mengelompokkan jenis cacat yang terjadi pada histogram, ketiga melakukan pembuatan scatter diagram untuk mengetahui trend yang terjadi, keempat melakukan pembuatan tabel FMEA serta usulan perbaikan untuk meminimalisir defect pada fishbone diagram.

\section{A. Six sigma}

Mempunyai fokus yang ketat, penerapan prinsip serta kualitas teknik yang terbukti efektif. Six Sigma bertujuan untuk mengetahui berapa banyak defect dalam satu juta peluang untuk mengukur tingkat sigma $(\alpha)$ pada proses kinerja 
bisnisnya[6]. Di sisi itu pula membagikan skala statistik pengukuran buat menunjang mengukur proses-proses revisi produk. Terdapat faktor penting yang jadi sasaran Six Sigma yakni tingkatkan kepuasan pelanggan, mengurangi siklus durasi, kurangi cacat yang terjadi[7].

\section{B. $\quad$ Fmea (Failure Mode Effect and Analysis)}

Kegagalan Mode dan Analisis Efek (FMEA) adalah teknologi sistem yang digunakan untuk menganalisis kegagalan, mendefinisikan, mengidentifikasi dan mengurangi masalah kegagalan yang diketahui dan / atau potensial, kesalahan dan / atau potensi sistem, desain, proses atau layanan sebelum mencapai konsumen[8].

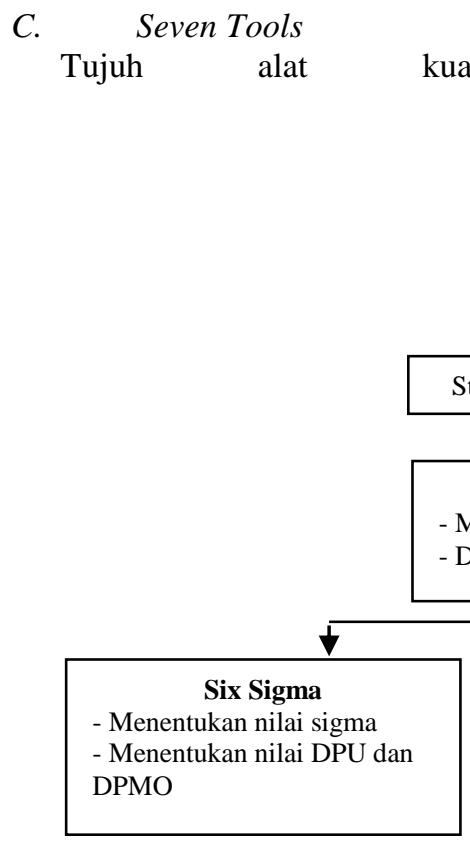

\section{HASIL PENELITIAN}

Setelah melakukan pengamatan dan menarik permasalahan yang ada di lapangan, selanjutnya menentukan metode yang cocok untuk menyelesaikan permasalahan tersebut. Maka, hasil dan pembahasan diterapkan[9]:identifikasi kecacatan yang terjadi dengan bantuan alat check sheet, diagram pareto untuk mengidentifikasi peringkat cacat terbanyak sampai paling sedikit, flow chart untuk membuat distribusi frekuensi pada bagian packaging, histogram untuk identifikasi distribusi yang ada, sebagai penentu apakah kecacatan masih pada batas toleransi di gunakan control chart dan scatter diagram untuk mengetahui hubungan antar plot data kecacatan dengan produksi serta menganalisis penyebab akar kecacatan pada fishbone diagram.

Dalam tahapan berikut, untuk mengetahui atribut obyek yang di teliti dan di lakukan tahap penelitian, dengan tahapan yang digunakan untuk mendapatkan data yang sesuai dengan kebutuhan penelitian yaitu: wawancara untuk mendapatkan data yang lebih akurat. Berikut alur penelitian :
- Mengidentifikasi proses produksi.

- Menentukan tingkat keparahan pada severity.

- Menentukan tingkat kejadian pada occurance

- Menentukan tingkat detection

- Menghitung nilai RPN

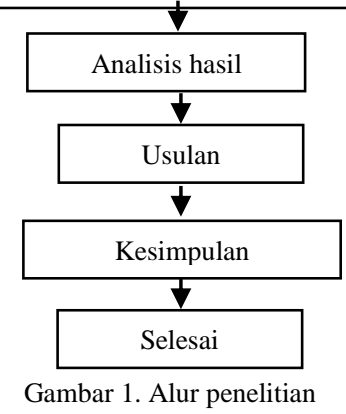

Studi lapangan

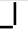

kerja.

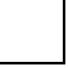

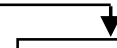
Seven Tools

-Membuat checksheet

-Membuat stratifikasi

-Membuat scatter diagram

-Membuat histogram

-Membuat diagram pareto

-Membuat peta kendali

-Memberikan usulan pada

fishbonediagram

permasalahan tersebut. Maka, hasil dan pembahasan

disajikan dari beberapa tahapan berikut :

\section{A. Define}

Merupakan salah satu proses awal dari metode Six Sigma untuk dapat mengetahui list daripada jumlah kecacatan, persentase cacat pada critical to quality (ctq) 
di masing-masing jenis cacat. Hasil checklist pada tanggal 2 februari 2021- 17 februari 2021 diberikan pada Tabel I.

Tabel I memperlihatakan jenis kecacatan pada packaging kedelai berdasarkan jumlah cacat terbesar yaitu karung sobek 75 karung, 57 karung pada gagal timbang dan jahitan lepas sebanyak 56 karung. Jumlah tersebut didasarkan bahwa 1 produk diterjemahkan oleh 1 jenis kecacatan paling fatal yang terlihat, dengan cacatan 1 produk memiliki lebih dari 1 jenis kecacatan.

TABEL I

DATA PRODUKSI DAN JENIS CACAT

\begin{tabular}{cccccc}
\hline & & & \multicolumn{3}{c}{ Jenis cacat } \\
\cline { 4 - 6 } No & Tgl & $\begin{array}{c}\text { Prod } \\
\text { uksi }\end{array}$ & $\begin{array}{c}\text { Gagal } \\
\text { Timb } \\
\text { ang }\end{array}$ & $\begin{array}{c}\text { Karun } \\
\text { g } \\
\text { Sobek }\end{array}$ & $\begin{array}{c}\text { Jahit } \\
\text { an } \\
\text { Lepa } \\
\text { s }\end{array}$ \\
\hline 1 & & & 4 & 5 & 4 \\
2 & $3 / 2 / 2021$ & 4000 & 5 & 4 & 3 \\
3 & $4 / 2 / 2021$ & 4160 & 7 & 5 & 4 \\
4 & $5 / 2 / 2021$ & 4560 & 3 & 5 & 2 \\
5 & $6 / 2 / 2021$ & 5200 & 3 & 6 & 6 \\
6 & $8 / 2 / 2021$ & 4520 & 3 & 6 & 2 \\
7 & $9 / 2 / 2021$ & 4240 & 2 & 5 & 2 \\
8 & $10 / 2 / 2021$ & 4760 & 5 & 6 & 4 \\
9 & $11 / 2 / 2021$ & 4320 & 3 & 5 & 5 \\
10 & $12 / 2 / 2021$ & 4320 & 5 & 6 & 6 \\
11 & $13 / 2 / 2021$ & 4800 & 3 & 5 & 5 \\
12 & $15 / 2 / 2021$ & 4000 & 6 & 4 & 3 \\
13 & $16 / 2 / 2021$ & 4320 & 4 & 5 & 7 \\
14 & $17 / 2 / 2021$ & 4520 & 4 & 8 & 3 \\
\hline & Jumlah & $\mathbf{6 1 2 8}$ & $\mathbf{5 7}$ & $\mathbf{7 5}$ & $\mathbf{5 6}$ \\
\hline & & & & &
\end{tabular}

1) Critical Quality Control (ctq) :

Produk cacat terdapat jenis cacat yang di analisis dengan pengklasifikasian data [10].Stratifikasi di sini bisa didapat dari hasil checklist, sehingga proses ini akan terdapat jumlah cacat dari kategori jenis cacat. Sehingga diketahui gambaran secara statistik, jenis cacat mana yang paling memberikan sumbangsih terbesar pada kegagalan produk. SATP mengklasifikasikan cacat berdasarkan 3 jenis, dengan data klasifikasi diberikan pada Tabel II.

TABEL II

CRITICAL TO QUALITY

\begin{tabular}{ccccc}
\hline No & $\begin{array}{c}\text { Jenis } \\
\text { Cacat }\end{array}$ & $\begin{array}{c}\text { Jumlah } \\
\text { Cacat }\end{array}$ & $\begin{array}{c}\text { Cacat } \\
\text { Kumulatif }\end{array}$ & $\begin{array}{c}\text { Persentas } \\
\text { e (\%) }\end{array}$ \\
\hline 1 & $\begin{array}{c}\text { Karung } \\
\text { sobek }\end{array}$ & 75 & 75 & $39.89 \%$ \\
2 & $\begin{array}{c}\text { Gagal } \\
\text { timbang }\end{array}$ & 57 & 132 & $30.32 \%$ \\
3 & $\begin{array}{c}\text { Jahitan } \\
\text { lepas }\end{array}$ & 56 & 188 & $29.79 \%$ \\
\hline & Jumlah & $\mathbf{1 8 8}$ & & $\mathbf{1 0 0 \%}$ \\
\hline
\end{tabular}

Tabel II menyajikan persentase jenis cacat tertinggi sebesar $39.89 \%$ pada jenis cacat karung sobek, gagal timbang sebesar $30.32 \%$ dan jahitan lepas sebesar $29.79 \%$, serta di lakukan pembuatan diagram pareto dan histogram (diagram lonceng) dengan minitab 16 untuk mengetahui rangking cacat tertinggi.

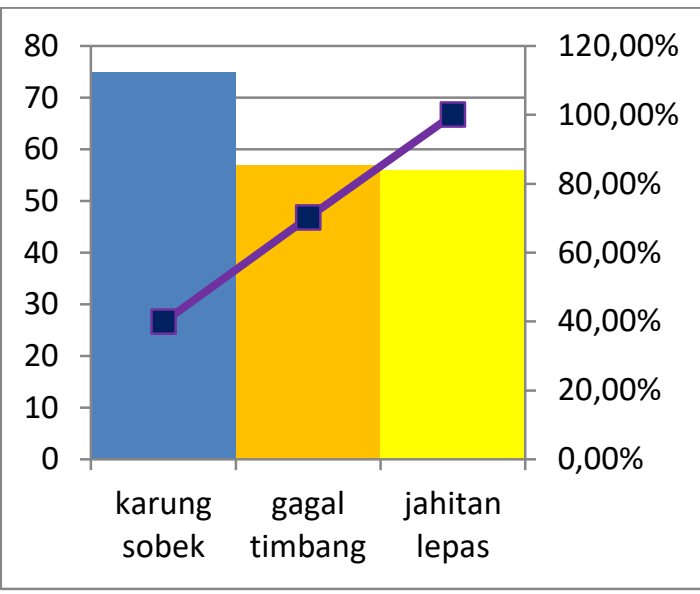

Gambar 2. Diagram pareto

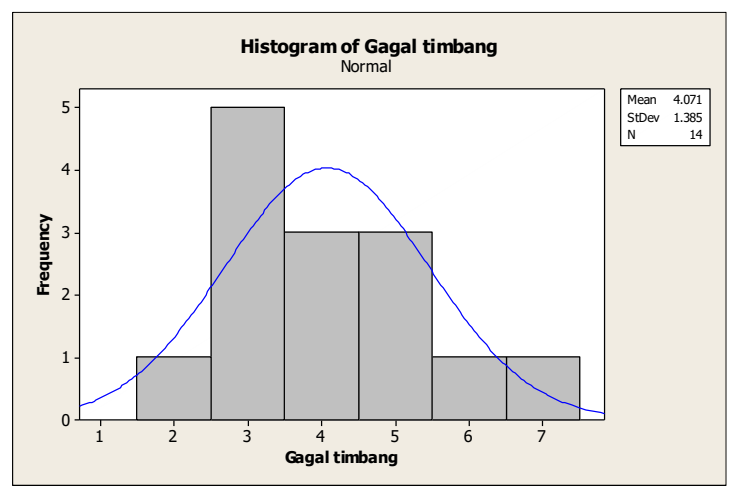

Gambar 3. Histogram gagal timbang

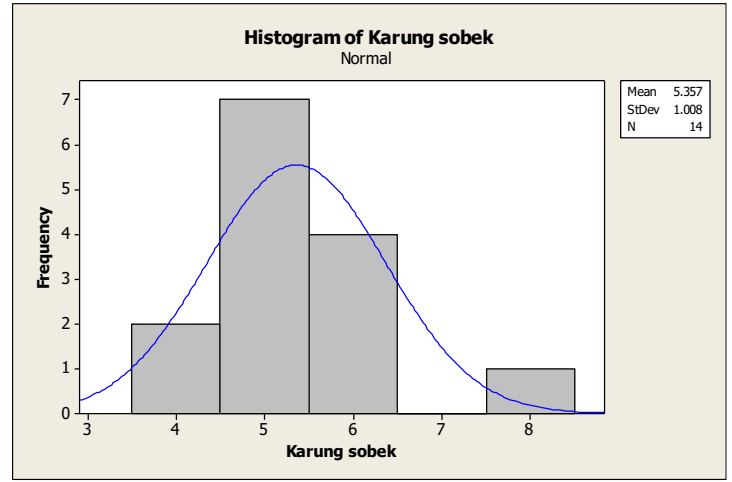

Gambar 4. Histogram karung sobek 
Jurnal Media

Teknik dan

Sistem Industri

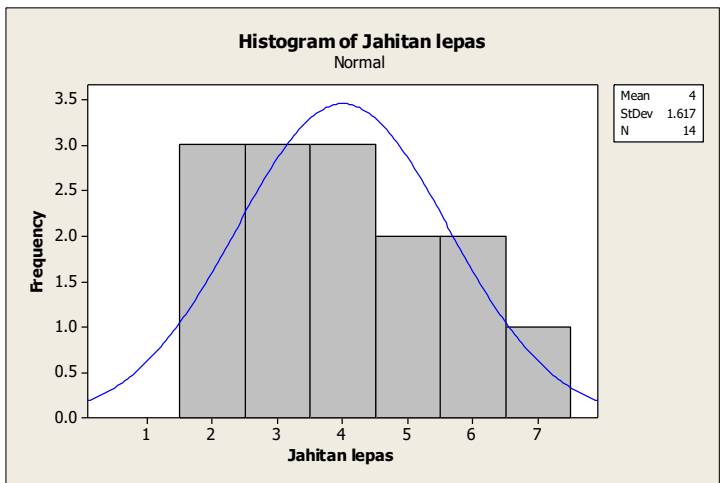

Gambar 5. Histogram jahitan lepas

B. $\quad$ Measure

Tahapan ini ialah langkah pengukuran buat mendapatkan data nilai pengukuran yang strategis yang digunakan pada tahapan berikutnya. Tahapan ini dicoba dengan pembuatan nilai batas atas, tengah dan bawah di peta kendali P pada Tabel III serta perhitungan nilai DPMO dan tingkat sigma.

- Persentase kerusakan (p)

$$
\begin{gathered}
: \frac{n p}{n}: \\
\text { Januari }: p: \frac{13}{3560}: 0,003652
\end{gathered}
$$

- $\quad$ Central line (cl)

$\mathrm{CL}: \bar{p}: \frac{\text { jumlahkecacatanperperiode }}{\text { jumlahproduksiperperiode }}$ :

$$
: \frac{188}{61280}: 0,003068
$$

- $\quad$ Upper control limit (ucl)

$$
\mathrm{Ucl} \bar{\Sigma}+3 \frac{\sqrt{\overline{\mathrm{p}(1-\overline{\mathrm{p}})}}}{\mathrm{n}}:
$$

$$
: 0.003652+3 \frac{\sqrt{0.003652(1-0.003652)}}{3560}: 0.0066845
$$

- $\quad$ Lower control limit (lcl)

$$
\text { Lcl : } \bar{p}-3 \frac{\sqrt{\overline{\mathrm{p}}(1-\overline{\mathrm{p}})}}{n}:
$$

$$
: 0.003652-3 \frac{\sqrt{0.003652(1-0.003652)}}{3560}=0.00025
$$

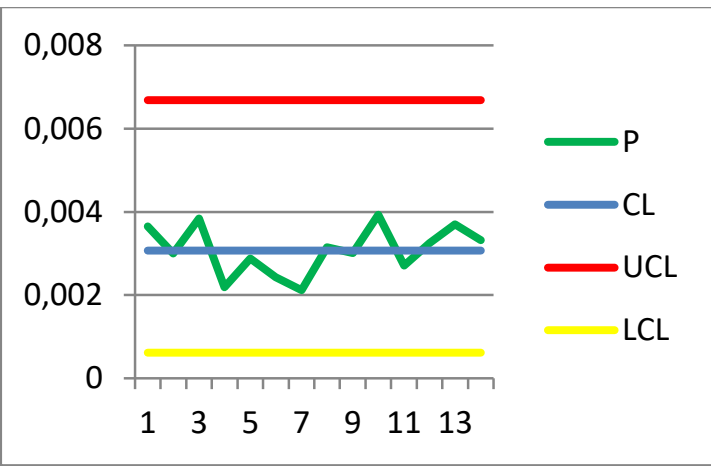

Gambar 6. Peta kendali

TABEL III

NILAI P, CL, UCLDAN LCL

\begin{tabular}{ccccc}
\hline $\begin{array}{c}\mathbf{N} \\
\mathbf{0}\end{array}$ & $\mathbf{P}$ & $\mathbf{C l}$ & $\mathbf{U c l}$ & $\mathbf{L c l}$ \\
\hline 1 & 0.003652 & 0.003068 & 0.0066845 & 0.0006189 \\
2 & 0.003000 & 0.003068 & 0.0066845 & 0.0006189 \\
3 & 0.003846 & 0.003068 & 0.0066845 & 0.0006189 \\
4 & 0.002193 & 0.003068 & 0.0066845 & 0.0006189 \\
5 & 0.002885 & 0.003068 & 0.0066845 & 0.0006189 \\
6 & 0.002434 & 0.003068 & 0.0066845 & 0.0006189 \\
7 & 0.002123 & 0.003068 & 0.0066845 & 0.0006189 \\
8 & 0.003151 & 0.003068 & 0.0066845 & 0.0006189 \\
9 & 0.003009 & 0.003068 & 0.0066845 & 0.0006189 \\
10 & 0.003935 & 0.003068 & 0.0066845 & 0.0006189 \\
11 & 0.002708 & 0.003068 & 0.0066845 & 0.0006189 \\
12 & 0.003250 & 0.003068 & 0.0066845 & 0.0006189 \\
13 & 0.003704 & 0.003068 & 0.0066845 & 0.0006189 \\
14 & 0.003319 & 0.003068 & 0.0066845 & 0.0006189 \\
\hline & & & &
\end{tabular}

Berdasarkan gambar 6, tidak adanya out of control pada data di peta kendali dan tidak perlu di lakukan revisi. Untuk data perlu di lakukan pengolahan di kemudian hari agar dapat mencapai tahap zero defect.

TABEL IV

NILAI DPU, DPMO DAN SIGMA

\begin{tabular}{ccccc}
\hline No & $\begin{array}{c}\text { Jumlah } \\
\text { defect/p } \\
\text { eriode }\end{array}$ & Dpu & Dpmo & $\begin{array}{c}\text { Sigma } \\
(\boldsymbol{\alpha})\end{array}$ \\
\hline 1 & 13 & 0.0002121 & 212.141 & 5.02 \\
2 & 12 & 0.0001958 & 195.822 & 5.05 \\
3 & 16 & 0.0002611 & 261.097 & 4.97
\end{tabular}




\begin{tabular}{|c|c|c|c|c|}
\hline No & $\begin{array}{c}\text { Jumlah } \\
\text { defect } / \mathrm{p} \\
\text { eriode }\end{array}$ & Dpu & Dpmo & $\begin{array}{l}\text { Sigma } \\
(\alpha)\end{array}$ \\
\hline 4 & 10 & 0.0022846 & 2284.60 & 4.34 \\
\hline 5 & 15 & 0.0002448 & 244.778 & 4.99 \\
\hline 6 & 11 & 0.0001795 & 179.504 & 5.07 \\
\hline 7 & 9 & 0.0001469 & 146.867 & 5.12 \\
\hline 8 & 15 & 0.0002448 & 244.778 & 4.99 \\
\hline 9 & 13 & 0.0002121 & 212.14 & 5.02 \\
\hline 10 & 17 & 0.0002774 & 277.415 & 4.95 \\
\hline 11 & 13 & 0.0002121 & 212.141 & 5.02 \\
\hline 12 & 13 & 0.0002121 & 212.141 & 5.02 \\
\hline 13 & 16 & 0.0002611 & 261.097 & 4.97 \\
\hline 14 & 15 & 0.0002448 & 244.778 & 4.99 \\
\hline \multicolumn{2}{|c|}{ Rata-rata } & 0.0003707 & 370.664 & 4.97 \\
\hline
\end{tabular}

1. Perhitungan Defect Per Unit (DPU)

$$
\text { DPU : } \frac{\text { Total kerusakan }}{\text { Total produksi }}: \frac{13}{61280} \text { : }
$$

\section{Perhitungan nilai DPMO}

DPMO : $D P U \times 1.000 .000$

$: 0.0002121 \times 1.000 .000: 212.141(11)$

\section{Perhitungan sigma $(\alpha)$}

$$
\begin{array}{r}
\text { Sigma }=\text { nomsinv } \frac{1.000 .000-D P U}{1.000 .000}+1.5(12) \\
\text { normsinv } \frac{1.000 .000-0.0002121}{1.000 .000}+1.5=5.02(13)
\end{array}
$$

\section{Analyse}

Pada tahap ketiga ini, peneliti membuat scatter diagram untuk mengetahui trend negative atau positif di perusahaan Sarana Agro Tama Persada serta membuat fishbone diagram agar di dapatkan penyebab permasalahan, berikut penjelasannya :

1. ScatterDiagram

Asumsi yang diterapkan disini, semakin banyak produk yang dihasilkan, maka peluang gagal produk juga ada. Scatter diagram akan memberikan celah hubungan antar jenis cacat. Singkat kata ketika 2 jenis cacat bahkan lebih saling berdampingan dan memiliki keeratan hubungan, maka dapat diidentifikasi secara statistik ada hubungan yang subjektif antar jenis cacat tersebut.

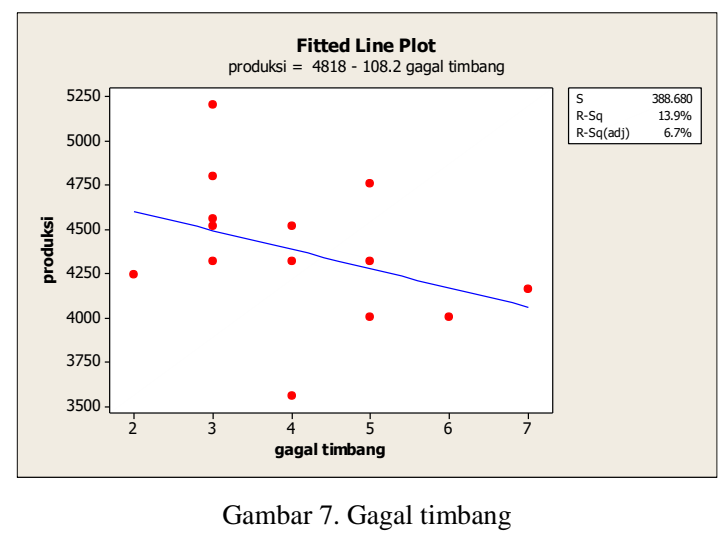

Pada gambar 7, di ketahui bahwa pada produk defect gagal timbang mendapati trend negatif, berarti adanya ketidaksesuaian antara produksi dengan defect yang terjadi.

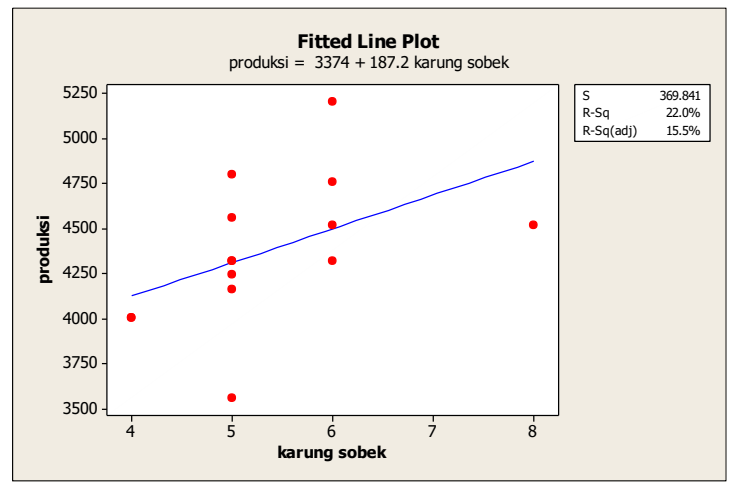

Gambar 8. Karung sobek

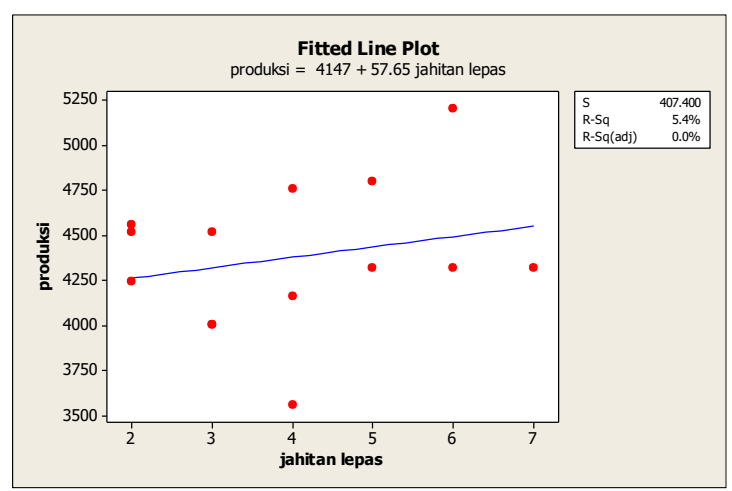

Gambar 9. Jahitan lepas

Pada gambar 8 dan 9, trend yang di dapat yaitu positif berarti antara tingkat jumlah kegagalan dan produksi masih selaras.

2. Fishbone diagram

Fishbone diagram juga dapat dipakai untuk mengetahui dan mengelompokkan sebab-akibat yang di dasari dari permasalahan tertentu., serta memisahkan penyebab pernasalahan yang terjadi [11]. Dari beberapa permasalahan yang muncul.. Fishbone sangat umum dijumpai di beberapa bidang. Alat ini dapat menerjemahkan suatu penyebab dari 
sebuah kondisi sistem yang nyata, sehingga bisa diberikan penanganan secara cepat. Fishbone tidak menargetkan nilai, tetapi hanya memberikan pandangan-pandangan penyebab dari yang terlihat nyata di lapangan menurut klasifikasinya. Fishbone diagram pada packaging di SATP disajikan sebagai pada gambar 10 di bawah ini.

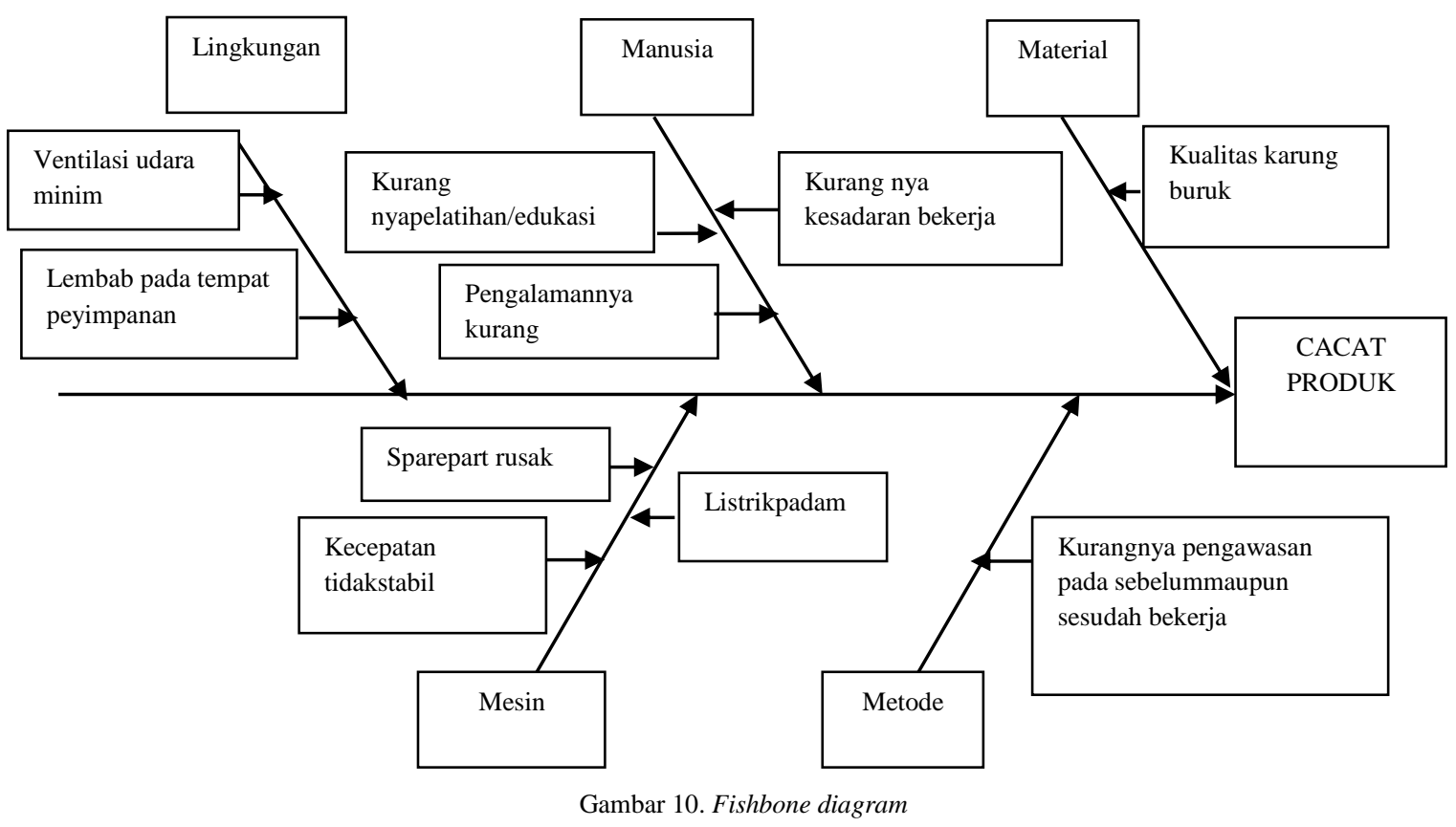

Gambar 10, di dapatkan adanya produk karung kemasan sobek,gagal timbang dan jahitan lepasdiakibatkan pemicu seperti mesin, metode yang digunakan, material, serta lingkungan yang menjadi penyebabnya. Fishbone diagram dilakukan untuk mencari faktor-faktor penyebab terjadinya cacat pada proses pengemasan kedelai.

\section{Improve}

Pada tahap keempat ini dengan dilakukannya pencarian penyebab pada permasalahan yakni menurunkan produk cacat dengan optimalisasi tahapan sebagai entitas produk kemasan yang berkualitas. Pada Tabel V di ketahui penyebab permasalahan dengan menggunakan FMEA, serta usulan perbaikan dengan metode seven tools yang sesuai hasil yang diharapkan. Berikut Tabel V dan VI di bawah ini.

TABEL V

FAILURE MODE AND EFFECT ANALYSIS (FMEA)

\begin{tabular}{|c|c|c|c|c|c|c|c|}
\hline $\begin{array}{c}\text { Jenis } \\
\text { Kecacatan }\end{array}$ & $\mathbf{S}$ & $\begin{array}{l}\text { Penyebab } \\
\text { Kecacatan }\end{array}$ & $\mathbf{O}$ & $\begin{array}{l}\text { Pengawasan } \\
\text { Yang } \\
\text { Dilakukan } \\
\end{array}$ & D & $\begin{array}{l}\text { Tindakan } \\
\text { Yang } \\
\text { Diberikan }\end{array}$ & Rpn \\
\hline \multirow[t]{4}{*}{$\begin{array}{l}\text { Karung } \\
\text { sobek }\end{array}$} & 7 & $\begin{array}{c}\text { Kualitas } \\
\text { karung } \\
\text { buruk }\end{array}$ & 7 & $\begin{array}{l}\text { Di lakukan } \\
\text { edukasi } \\
\text { pemilihan } \\
\text { karung } \\
\end{array}$ & 5 & $\begin{array}{c}\text { Meningkatkan } \\
\text { pemahaman } \\
\text { khusus }\end{array}$ & 245 \\
\hline & & $\begin{array}{l}\text { Kurang nya } \\
\text { edukasi } \\
\text { pemilihan } \\
\text { karung } \\
\end{array}$ & 5 & $\begin{array}{c}\text { Di berikan } \\
\text { pemahaman } \\
\text { karung yang } \\
\text { baik } \\
\end{array}$ & 6 & $\begin{array}{l}\text { Di lakukan } \\
\text { briefing } \\
\text { sebelum } \\
\text { bekerja } \\
\end{array}$ & 210 \\
\hline & & $\begin{array}{l}\text { Terdapatnya } \\
\text { benda tajam } \\
\text { pada mesin }\end{array}$ & 4 & $\begin{array}{c}\text { Pemahaman } \\
\text { kebersihan } \\
\text { sebelum/setelah } \\
\text { bekerja }\end{array}$ & 4 & $\begin{array}{l}\text { Melakukan } \\
\text { pemeriksaan } \\
\text { yang intensif }\end{array}$ & 112 \\
\hline & & $\begin{array}{c}\text { Kecepatan } \\
\text { mesin tidak } \\
\text { stabil }\end{array}$ & 4 & $\begin{array}{l}\text { Melakukan } \\
\text { maintenance } \\
\text { pada mesin }\end{array}$ & 5 & $\begin{array}{l}\text { Melakukan } \\
\text { pemeliharaan } \\
\text { mein secara } \\
\text { rutin }\end{array}$ & 140 \\
\hline $\begin{array}{c}\text { Jahitan } \\
\text { lepas }\end{array}$ & 5 & $\begin{array}{l}\text { Jarum } \\
\text { tumpul }\end{array}$ & 5 & $\begin{array}{l}\text { Mengganti } \\
\text { jarum yang }\end{array}$ & 3 & $\begin{array}{l}\text { Melakukan } \\
\text { pengarahan }\end{array}$ & 75 \\
\hline
\end{tabular}




\begin{tabular}{|c|c|c|c|c|c|c|c|}
\hline \multirow[t]{4}{*}{$\begin{array}{c}\text { Jenis } \\
\text { Kecacatan }\end{array}$} & $\mathbf{S}$ & $\begin{array}{l}\text { Penyebab } \\
\text { Kecacatan }\end{array}$ & O & $\begin{array}{c}\text { Pengawasan } \\
\text { Yang } \\
\text { Dilakukan }\end{array}$ & D & $\begin{array}{l}\text { Tindakan } \\
\text { Yang } \\
\text { Diberikan }\end{array}$ & Rpn \\
\hline & & & & baru & & $\begin{array}{l}\text { pada } \\
\text { pergantian } \\
\text { jarum }\end{array}$ & \\
\hline & & $\begin{array}{c}\text { Benang stok } \\
\text { lama }\end{array}$ & 4 & $\begin{array}{c}\text { Memakai stok } \\
\text { benang yang } \\
\text { baru }\end{array}$ & 3 & $\begin{array}{c}\text { Melakukan } \\
\text { penyediaan } \\
\text { benang yang } \\
\text { baru }\end{array}$ & 60 \\
\hline & & $\begin{array}{l}\text { Listrik } \\
\text { padam }\end{array}$ & 6 & $\begin{array}{l}\text { Menyediakan } \\
\text { generator }\end{array}$ & 6 & $\begin{array}{l}\text { Melakukan } \\
\text { pembelian } \\
\text { generator }\end{array}$ & 120 \\
\hline \multirow[t]{3}{*}{$\begin{array}{c}\text { Gagal } \\
\text { timbang }\end{array}$} & 6 & $\begin{array}{l}\text { Timbangan } \\
\text { tidak sesuai }\end{array}$ & 6 & $\begin{array}{c}\text { Melakukan } \\
\text { kalibrasi }\end{array}$ & 4 & $\begin{array}{c}\text { Menjadwalkan } \\
\text { pemeliharaan } \\
\text { mesin yang } \\
\text { sesuai }\end{array}$ & 144 \\
\hline & & $\begin{array}{c}\text { Ventilasi } \\
\text { udara } \\
\text { kurang }\end{array}$ & 7 & $\begin{array}{c}\text { Menambah } \\
\text { ventilasi udara }\end{array}$ & 5 & $\begin{array}{c}\text { Melakukan } \\
\text { pembuatan } \\
\text { sirkulasi udara } \\
\end{array}$ & 210 \\
\hline & & $\begin{array}{c}\text { Terdapat } \\
\text { spere part } \\
\text { yang rusak }\end{array}$ & 5 & $\begin{array}{c}\text { Mengganti } \\
\text { spare part yang } \\
\text { rusak }\end{array}$ & 5 & $\begin{array}{c}\text { Melakukan } \\
\text { penyediaan } \\
\text { spare part } \\
\text { mesin }\end{array}$ & 150 \\
\hline
\end{tabular}

TABEL VI

USULAN PERBAIKAN

\begin{tabular}{|c|c|c|c|}
\hline No & Faktor & Sebab & Perbaikan \\
\hline \multirow[t]{2}{*}{1} & Manusia & $\begin{array}{l}\text { Kurang nya pelatihan dan } \\
\text { Pengalaman kurang }\end{array}$ & $\begin{array}{l}\text { Dengan di beri pelatihan ,wawasan dan edukasi pada } \\
\text { pekerja, serta di adakan pertemuan sebelum bekerja guna } \\
\text { mengevaluasi pekerjaan kemarin dan pekerjaan saat ini. }\end{array}$ \\
\hline & & Kurangnya kesadaran & $\begin{array}{l}\text { Memberikan teguran agar para pekerja menjalankan } \\
\text { pekerjaan sesuai pada job desk.. }\end{array}$ \\
\hline \multirow[t]{3}{*}{2} & Mesin & Spare part ada yang rusak & $\begin{array}{l}\text { Mengganti part yang rusak serta menyiapkan cadangan } \\
\text { spare part, bilamana terjadi kerusakan lagi }\end{array}$ \\
\hline & & Kecepatan mesin tidak stabil & $\begin{array}{l}\text { Melakukan maintenance / perawatan berkala setiap } \\
\text { minggunya pada mesin packaging maupun kalibrasi ulang } \\
\text { pada timbangan }\end{array}$ \\
\hline & & Listrik padam & Melakukan penyediaan generator \\
\hline 3 & Metode & $\begin{array}{l}\text { Kurangnya } \text { pengawasan } \\
\text { maupun Perawatan sebelum } \\
\text { dan setelah menggunakan } \\
\text { mesin }\end{array}$ & $\begin{array}{l}\text { Dilakukannya pengawasan pada setiap lini pekerjaan secara } \\
\text { berkala, Di berlakukan standard operating procedure } \\
\text { kepada pekerja, Diintstruksikan kebersihan di area kerja } \\
\text { pada pekerja }\end{array}$ \\
\hline 4 & Material & $\begin{array}{l}\text { Kurang teliti pada pengecekan } \\
\text { kualitas karung }\end{array}$ & $\begin{array}{l}\text { Dengan dilakukannya pengawasan yang ekstra serta } \\
\text { wawasan mengenai kualitas barang yang baik. }\end{array}$ \\
\hline 5 & $\begin{array}{l}\text { Lingkun } \\
\text { gan }\end{array}$ & $\begin{array}{lr}\text { Kurangnya } & \text { sirkulasi } \\
\text { udara/ventilasi } & \text { menjadi } \\
\text { lembap di area } & \text { penyimpanan } \\
\text { kedelai } & \end{array}$ & $\begin{array}{l}\text { Di buatnya sirkulasi udara pada gudang penyimpanan agar } \\
\text { tidak terjadi penyusutan pada kedelai. }\end{array}$ \\
\hline
\end{tabular}

E.

Control

Tahapan ini di pergunakan sebagai pengendalian kualitas dari konsekuensi perhitungan nilai Sigma $(\alpha)$. Menurut [14] untuk melaksanakan control pada proses pembuatan genteng ialah memakai check sheet untuk menetapkan, jika kombinasi tingkat aspek yang digunakan cocok dengan kombinasi tingkat aspek yang maksimal, sesudah dilakukan riset. Digunakan Alat pengendali kualitas, yaitu: check sheet, scatter diagram, fishbone diagram serta peta kendali $p$, bahwa tidak ada data yang keluar jalur (out of control).

\section{PEMBAHASAN}

Berdasarkan hasil analisa mengenai DMAIC yang telah dipaparkan pada hasil pembahasan, di dapat

hasil brainstorming dengan masing-masing divisi pada lini kerja di PT. Sari Agro Tama Persada dan juga peneliti, maka usulan perbaikan yang bisa diberikan sebagai berikut :

Permasalahan ini sesuai dengan pernyataan[12] yang menjelaskan bahwa untuk memangkas produk cacat sepatu di PT. Halim Jaya Sakti salah satu langkah untuk memperbaikinya yaitu dengan menyeleksi calon karyawan berdasarkan kualitas. Sedangkan menurut [13] untuk meningkatkan perusahaan agar tepat dan efektif pada suatu pekerjaan, perlu kecermatan serta 
ketelitian dalam memilih pekerja yang sesuai kebutuhan perusahaan. Dari faktor tersebut, membuat dan

memperbaiki alur kerja secara rinci, dan analisis kekurangan metode atau alur kerja perusahaan tersebut.

\section{KESIMPULAN}

Terdapatnya hasil penelitian karung sobek merupakan cacat tertinggi pada packaging kedelai sebesar 75 karung dan persentase $30.89 \%$, sedangkan terdapatnya trend negative gagal timbang yang dikarenakan tidak validnya angka timbangan dan perlunya di kalibrasi sesuai dengan prosedur yang ada.

Berdasarkan penghitungan nilai DPMO yang telah dilakukan didapat nilai tertinggi 2284.595 terjadi pada 5 Februari 2021, berarti dalam 1.000.000 packaging yang diproduksi terdapat sebanyak 2284.595 kemasan yang tidak memenuhi kriteria kualitas dari PT SATP. Sedangkan nilai $\operatorname{sigma}(\alpha)$ sebesar 4.97 yang hampir mendekati skala industri kelas dunia.

Usulan perbaikan pengendalian kualitas yang terdapat pada fishbone diagram, yaitu: menegur pekerja bilamana melakukan kesalahan, di lakukan briefieng/safety talk pada sebelum bekerja, melakukan pengecekan mesin, serta mementingkan ketersediaan spare part (jarum jahit), melakukan kalibrasi rutin pada mesin timbangan.

Saran yang dapat diberikan adalah kepada pihak perusahaan (SATP) di harapkan memperbaiki usulan dari peneliti untuk meminimasi semua jenis cacat yang terjadi. Untuk penelitian selanjutnya, diharapkan dapat meningkatkan kualitas proses produksi dengan menggunakan metode-metode yang lain, agar bisa di bandingkan dan mendapatkan hasil yang lebih baik ke depannya.

\section{REFERENSI}

[1] I Gusti Agung Ayu Istri Lestari, "Penerapan Sistem Manajemen Mutu Iso 9001:2008 Di Perusahaan Konstruksi," Ganec Swara, Vol. 9, No. 1, Pp. 121-126, 2015.

[2] D. Meidiarti, "Pengendalian Kualitas Produk Cacat Batang Alumunium Ec Grade Menggunakan Pendekatan Failure Mode And Effect Analysis," J. Ilm. Tek. Ind., Vol. 8, No. 1, Pp. 18-24, 2020, Doi: 10.24912/Jitiuntar.V8i1.6341.

[3] Pusat Data Dan Sistem.Informasi Pertanian Kementerian Pertanian, Outlook Komoditas Pertanian Tanaman Pangan Kedelai. Indonesia: Kementrian Pertanian, 2016.

[4] P. Wisnubroto And M. Yogi, "Pengendalian Kualitas Produk Dengan Metode Six Sigma, Seven Tools, Dan Kaizen Untuk Mengurangi Produk Cacat Di Pt. Mitra Rekatama Mandiri,” Tekinfo, Vol. 5, No. 1, Pp. 1-21, 2016.

[5] A. Librianty And R. T. Yuliarto, "Pengaruh Kualitas Pelayanan Terhadap Kepuasan Pelanggan Pada Bengkel
Syakira," Aset, Vol. 21, No. 1, Pp. 1-7, 2019, [Online]. Available: Http://Eprints.Ums.Ac.Id/Id/Eprint/79577.

[6] T. Pyzdek And P. Keller, The Six Sigma Handbook, Fourth Edi. United States: Mcgraw-Hill, 2014.

[7] A. Efendik, N. Luh, And P. Hariastuti, "Pengendalian Kualitas Produk Dengan Pendekatan Six Sigma Dan Serta Seven Tools Sebagai Usaha Pengurangan Kecacatan Produk Pada Cv. Prima Perkasa,” Inst. Teknol. Adhi Tama Surabaya, Vol. Vi, Pp. 351-356, 2018.

[8] M. Kholil, D. S. Oktaandhini, And A. Suparno, "Lean Six Sigma Untuk Mengurangi Waste Pada Produksi Tablet Coating A," J. Penelit. Dan Apl. Sist. Tek. Ind. (Pasti, Vol. Xiv, No. 3, Pp. 255-267, 2020.

[9] S. Muhammad, "Quality Improvement Of Fan Manufacturing Industry By Using Basic Seven Tools Of Quality: A Case Study," J. Eng. Res. Appl. Www.Ijera.Com, Vol. 5, No. 4, Pp. 30-35, 2015, [Online]. Available: Www.Ijera.Com.

[10]M. M. Retno Any Asmoro, "Journal Knowledge Industrial Engineering ( Jkie )," Anal. Prod. Reject Pada Prod. 600 Ml Dengan Metod. Seven Tools Di Pt. Tirta Investama Pandaan, Pp. 1-14, 2017, [Online]. Available: Http://Jurnal.Yudharta.Ac.Id/V2/Index.Php/Jkie/Article/Vi ew/863/727.

[11]C. E. Widyahening, "Penggunaan Teknik Pembelajaran Fishbone diagram Dalam Meningkatkan Keterampilan Membaca Siswa," J. Komun. Pendidik., Vol. 2, No. 1, P. 11, 2018, Doi: 10.32585/Jkp.V2i1.59.

[12]F. Kusuma, "Pengendalian Kualitas Sepatu Dengan Menggunakan Metode Seven Tools Di Pt. Halim Jaya Sakti Pasuruan," Calyptra J. Ilm. Mhs. Univ. Surabaya, Vol. 6, No. 2, Pp. 1299-1309, 2017.

[13] A. Sasongko, I. F. Astuti, And S. Maharani, "Pemilihan Karyawan Baru Dengan Metode Ahp (Analytic Hierarchy Process)," Inform. Mulawarman J. Ilm. Ilmu Komput., Vol. 12, No. 2, P. 88, 2017, Doi: 10.30872/Jim.V12i2.650.

[14] S. K. Dewi And D. M. Ummah, "Perbaikan Kualitas Pada Produk Genteng Dengan Metode Six Sigma," J@Ti Undip J. Tek. Ind., Vol. 14, No. 2, Pp. 87-92, 2019, Doi: 10.14710/Jati.14.2.87-92 